\title{
Evaluation of the Genotoxic Potential of the Selective COX-2 Inhibitor Enflicoxib in a Battery of in vitro and in vivo Genotoxicity Assays
}

\section{() (1) $(8)$}

\author{
Authors \\ Antonio Guzmán ${ }^{1}$, Josep Homedes², Marta Salichs²
}

\section{Affiliations}

1 Welab Barcelona. Barcelona Science Park, C/Baldiri Reixac 4-8, Barcelona - Spain

2 Ecuphar Veterinaria S.L.U. (Animalcare Group). Avgda. Río de Janeiro 60 - 66, planta 13, Barcelona - Spain

Key words

Enflicoxib, Daxocox, Genotoxicity, Mutagenesis, COX-2

received 31.08 .2021

accepted 16.11 .2021

published online 18.01 .2022

Bibliography

Drug Res 2022; 72: 163-170

DOI 10.1055/a-1727-5733

ISSN 2194-9379

(c) 2022. The Author(s).

This is an open access article published by Thieme under the terms of the Creative Commons Attribution-NonDerivative-NonCommercial-License, permitting copying and reproduction so long as the original work is given appropriate credit. Contents may not be used for commecial purposes, or adapted, remixed, transformed or built upon. (https://creativecommons. org/licenses/by-nc-nd/4.0/)

Georg Thieme Verlag KG, Rüdigerstraße 14,

70469 Stuttgart, Germany

\section{Correspondence}

Josep Homedes

Ecuphar Veterinaria S.L.U. (Animalcare Group)

Avgda. Río de Janeiro 60 - 66

planta 13

08016 Barcelona

Spain

Tel.: + 34629161399

jhomedes@ecuphar.es

\section{ABSTRACT}

Aim Enflicoxib, a selective COX-2 inhibitor approved for the treatment of pain and inflammation associated with osteoarthritis in dogs (Daxocox ${ }^{\circledR}$ [Ecuphar/Animalcare Group]) was assessed for its genotoxic potential in a battery of in vitro and in vivo genotoxicity assays. These comprised a bacterial reverse mutation assay (Ames test), an in vitro human lymphocyte chromosome aberration assay and an in vivo mouse bone marrow micronucleus assay.

Methods Relevant vehicle and positive control cultures and animals were included in all assays. In the Ames test, enflicoxib was tested at concentrations of up to $5000 \mu \mathrm{g} /$ plate. Signs of cytotoxicity were observed at the highest tested concentrations for several of the bacterial strains, both in absence and presence of S9. In human lymphocytes, enflicoxib was assessed for the induction of chromosomal aberrations when exposed at concentrations of up to 62.5 ( 3 hours) and $29.6 \mu \mathrm{g} / \mathrm{mL}$ ( 20 hours) in the absence of $S 9$, and up to $66.7 \mu \mathrm{g} / \mathrm{mL}$ ( 3 hours) in presence of S9. Signs of cell toxicity, evidenced as a decrease in the mitotic index, were observed at these concentrations. In the mouse micronucleus assay, enflicoxib dose levels of up to $2000 \mathrm{mg} / \mathrm{kg}$ were administered (single dose) to male and female animals, and bone marrow samples were taken 24 and 48 hours (high-dose animals only) after administration.

Results Enflicoxib was shown to lack genotoxic activity in the conducted assays.

Conclusions The administration of enflicoxib as a therapeutic analgesic agent would not pose a genotoxic risk to animals or humans.

\section{Introduction}

Enflicoxib (also known by its research acronym E-6087) is a new pyrazoline derivative COX-2 inhibitor showing potent anti-inflammatory and analgesic activity when tested in experimental models of inflammation and pain in laboratory animals ( $>$ Fig. 1) [1] and in dog [2]. It has also shown to be effective in field clinical trials [3] with a broad safety margin when administered as recommended in dogs [4]. Enflicoxib has recently been approved for commercial veterinary use in Europe as Daxocox ${ }^{\circledR}$ tablets for dogs (Ecuphar NV/ Animalcare) for the treatment of pain and inflammation associated with osteoarthritis in dogs, administered at a weekly dose of $4 \mathrm{mg} / \mathrm{kg}$ with an initial loading dose of $8 \mathrm{mg} / \mathrm{kg}$ [2]. 


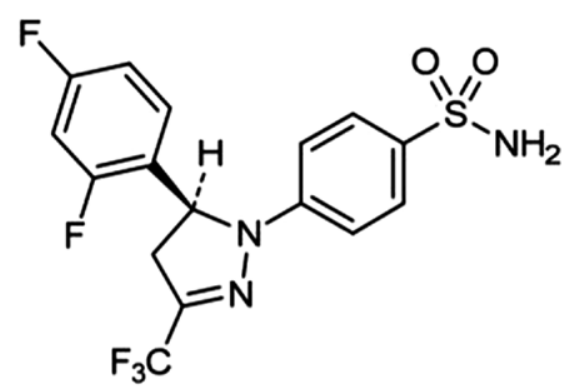

Fig. 1 Chemical structure of enflicoxib.

Assessment for genotoxic potential is a mandatory step in the development process of a new pharmaceutical, as the exposure to agents with genotoxic activity is considered associated to the potential for induction of carcinogenesis and hereditary defects. It is therefore a common regulatory requirement to assess the genotoxic potential of both human and veterinary pharmaceuticals $[5,6]$. To reduce the risk of genotoxic compounds not being properly detected, human and veterinary pharmaceuticals are required to be tested in a battery comprised of in vitro and in vivo genotoxicity assays $[7,8]$. According to current veterinary legislation this generally comprises, assessment for induction of gene mutation in bacteria, in vitro chromosomal damage and/or gene mutation in mammalian cells, and an in vivo test assessing chromosomal damage in rodent haematopoietic cells.

We report here the results that were obtained when enflicoxib was assessed for genotoxic potential in a battery of GLP compliant in vitro and in vivo genotoxicity assays conducted according to internationally accepted standards. For this purpose, enflicoxib was tested in a bacterial reverse mutation assay (Ames test), an in vitro chromosome aberration assay in human lymphocytes and an in vivo mouse bone marrow micronucleus assay. The results obtained in these studies and their relevance for animal and human risk assessment is discussed in this manuscript.

\section{Methods}

\section{Test substances}

Enflicoxib (1-(4-aminosulfonylphenyl)-5-(2,4-difluorophenyl)-4,5dihydro- 3-trifluoromethyl-1H-pyrazole, CAS 251442-94-1) was synthesized by Esteve Pharmaceuticals (Barcelona, Spain). Test item solutions were prepared by dissolving enflicoxib in dimethyl sulfoxide (DMSO) for the Ames test and the Chromosome Aberration assay. For the in vivo mouse micronucleus test enflicoxib was formulated as a suspension in $0.5 \%$ methylcellulose. For in vitro studies, a stock solution was prepared at the maximum concentration required for the treatment and was diluted in appropriate sterile solvent to reach the required concentrations. Purity of enflicoxib was at least $99.5 \%$. Vehicles used for enflicoxib formulation were used as negative controls in the corresponding assays. Enflicoxib formulations were prepared immediately prior to testing. Positive control chemicals were obtained from the following suppliers: cyclophosphamide (CP, Sigma), ethylmethanesulfonate (EMS, Sigma), 2 Nitrofluorene (2NF, Aldrich), Sodium azide ( $\mathrm{NaN}_{3}$, Sigma), 4-Nitroquinoline oxide (4NQ, Sigma), 9-Aminoacridine (9AC, Sigma), and 2-Aminoanthracene (2-AA, Aldrich). For treatment, $\mathrm{CP}$ and $\mathrm{NaN}_{3}$ were dissolved in water, EMS, 2NF, 4NQ, 9AC and 2-AA were dissolved in DMSO.

\section{Metabolic activation system}

For in vitro assays, commercial mammalian rat liver post-microsomal fraction (S9) was used as an exogenous metabolic activation system. S9 fractions prepared from male Sprague Dawley rat livers induced with Aroclor 1254 were obtained from Trinova Biochem GMBH (Gieben, Germany) and from ICN (USA) for the Ames test and chromosomal aberrations tests, respectively. $S 9$ fractions were stored frozen at approximately $-80^{\circ} \mathrm{C}$, thawed just prior to use and supplemented with a NADPH-generating system (S9-mix). Final concentration of S9 fraction in the S-9 mix was $10 \%$ for all in vitro assays.

\section{Ames test}

The method was carried out following the recommendations of Maron and Ames [9] and according to the corresponding OECD guideline [10]. Four Salmonella typhimurium histidine auxotrophic strains (TA98, TA100, TA1535 and TA1537) and an Escherichia coli tryptophan requiring strain (WP2 uvrA pKM101) were used. Salmonella strains TA98, TA100 and TA1535 were obtained from CECT (Spanish Collection of Type Cultures, Valencia, Spain), Salmonella strains TA1537 was obtained from Moltox (USA) and Escherichia coli strain from DSMZ (German Collection of Microorganisms and Cell Cultures, Germany). A frozen sample of each tester strain was thawed and grown in NB2 culture media until late-exponential culture phase. The potential for the solubility or cytotoxicity of enflicoxib to act as a dose limiting factor in the test system was assessed in a preliminary study with strain TA100 both in absence and presence of metabolic activation (results not shown).

The main study comprised two independent experiments performed on different days and using fresh cultures of each bacterial strain. Experiment 1 was performed by means of the direct plate incorporation method while Experiment 2 was carried out by means of the preincubation method. All experiments were performed both in absence and presence of metabolic activation, using triplicate plates for each tested substance and treatment condition. Tested concentrations and conditions are detailed in $>$ Table 1. DMSO was used as negative control. 2NF, AZ, 4NQ, 9AC and 2-AA were used as positive controls. Briefly, $0.1 \mathrm{~mL}$ of test item (or control solutions), $0.1 \mathrm{~mL}$ of bacterial culture and $0.5 \mathrm{~mL}$ of $\$ 9$ mix (or phosphate buffer solution for treatments in absence of metabolic activation) were mixed and poured on to Vogel Bonner-E minimal agar plates after addition of $2 \mathrm{~mL}$ of top agar at $42^{\circ} \mathrm{C}$. In Experiment 2 , this mix was incubated for $20 \mathrm{~min}$ at $37^{\circ} \mathrm{C}$, before addition of $2 \mathrm{~mL}$ molten agar at $42^{\circ} \mathrm{C}$.

Plates were inverted and incubated for $48-72$ hours at $37^{\circ} \mathrm{C}$ in the dark. Revertant colonies were counted by means of a Sorcerer image analyzer system (Perceptive Instruments) and the background lawn inspected for signs of toxicity or compound precipitation. From the individual plate counts the mean number of rever- 


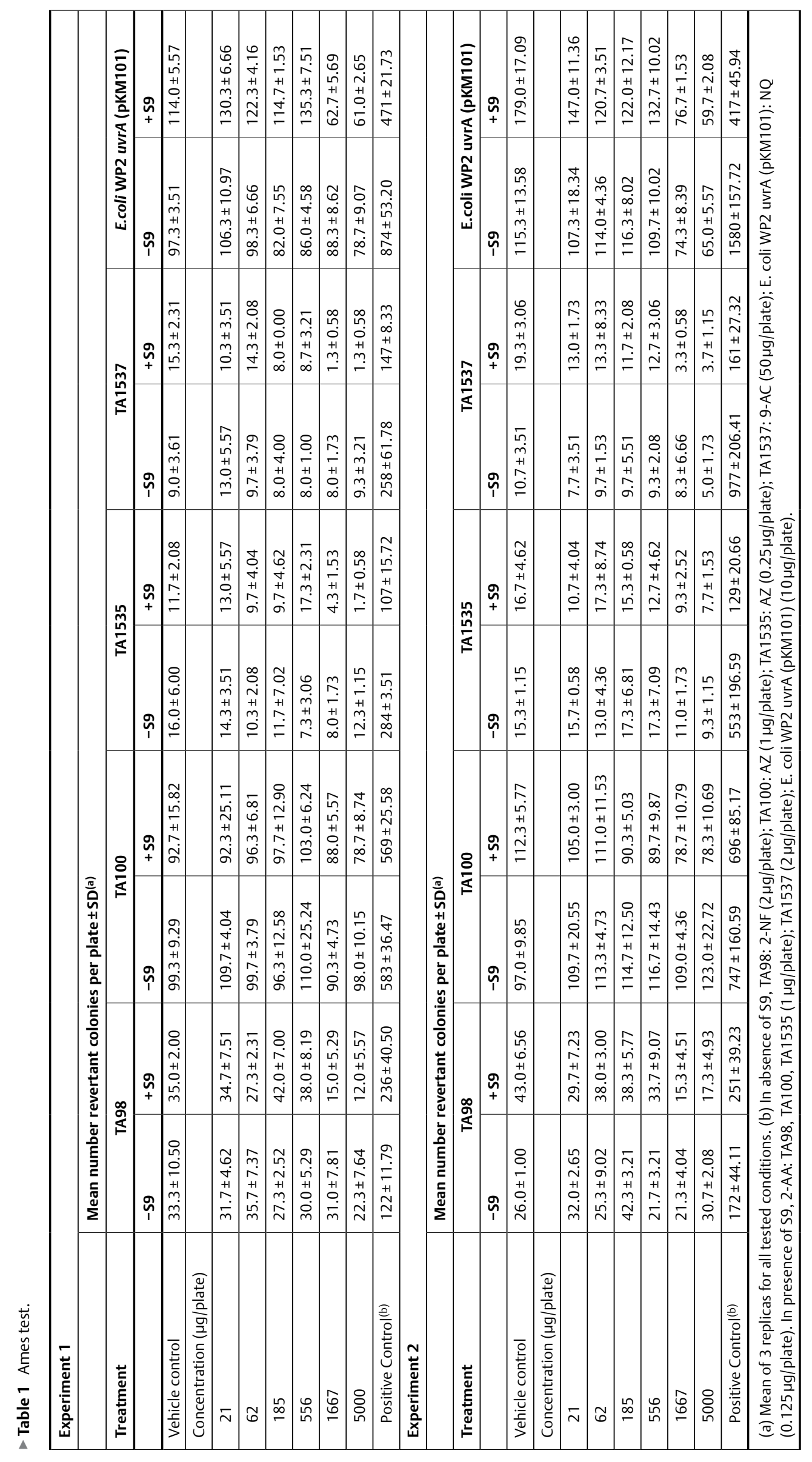


tants and standard deviation (SD) for each test item, concentration and experimental condition were determined. The assay was considered positive for mutagenic activity when there was a greater than 2 -fold increase in the mean number of revertants versus the mean number of spontaneous revertants obtained in the vehicle control in any of the test strains, and a dose-response effect was observed.

\section{Human lymphocyte chromosome aberration assay}

The test was conducted following the method described by Dean and Danford [11] and following the recommendations of the corresponding OECD guideline [12]. Two independent experiments were performed. Whole blood heparinized $(50 \mathrm{IU} / \mathrm{mL})$ samples were obtained from healthy non-smoking adults (male and a female subject for Experiments 1 and 2, respectively). Cultures were established by placing $0.5 \mathrm{~mL}$ of whole blood into $9.5 \mathrm{ml}$ RPMI 1640 Dutch-modified medium supplemented with $10 \%$ foetal calf serum, $50 \mu \mathrm{g} / \mathrm{mL}$ streptomycin, $50 \mathrm{IU} / \mathrm{mL}$ penicillin, $5 \mu \mathrm{g} / \mathrm{mL}$ phytohaemaglutinin and $1 \mathrm{IU} / \mathrm{mL}$ heparin. Cultures were incubated for approximately 48 hours at $37^{\circ} \mathrm{C}$ in a $5 \%$ of $\mathrm{CO}_{2}$ environment and shaken gently during culture period, prior to the start of treatment. For each treatment condition, duplicate cultures for each enflicoxib concentration and positive controls and quadruplicate cultures for vehicle control were set up. Tested concentrations and conditions are detailed in $>$ Table 2 . Vehicle-control cultures were treated with DMSO, and positive control cultures with EMS and CP in the absence and presence of $S 9$, respectively. Enflicoxib and controls were administered at $1 \%(v / v)$ into the culture media. In Experiment 1 , cultures were treated for 3 hours in absence and presence of S9 followed by 17 hours recovery. In Experiment 2, cultures were treated for 3 hours in presence of $\$ 9$, followed by a 17 hours recovery period, while cultures treated in absence of $\$ 9$ were exposed continuously for 20 hours to enflicoxib.

The concentration of S9-mix in the treatment medium was $10 \%$ (final concentration of S9, $1 \%$ ). After the 3 hours treatment period in presence or absence of S9 mix, cells were washed twice with sterile saline and resuspended in fresh medium for the completion of the recovery phase. Colcemid (Serva) at a final concentration of $0.4 \mu \mathrm{g} /$ $\mathrm{mL}$ was added 3 hours prior to harvest. Cells were collected by centrifugation (10 minutes $600 \mathrm{~g}$ ), resuspended in potassium chloride hypotonic solution $(0.075 \mathrm{M})$ for 20 minutes and fixed in ice-cold methanol/glacial acetic acid solution $(3: 1, v / v)$. Several drops of the cell suspension were spread on microscope slides. The slides were air-dried and stained with Giemsa $5 \%$ in Sorensen buffer at pH 6.8 for 5 minutes. To assess cytotoxic/cytostatic effects, the mitotic index (MI) for each culture was established by examining the presence of metaphases in 1000 cell nuclei. After MI assessment, three test substance concentrations (with and without S9) were selected for cytogenetic analysis. For vehicle and positive controls and each test substance concentration, 200 well-spread metaphase figures were analysed for the presence of structural chromosomal aberrations (100/culture). The classification of structural aberrations was carried following the guidance of the International System for Cytogenetic Nomenclature [13]. The presence of polyploid, endoreduplicated and hyperdiploid cells was also recorded. For each treatment condition the proportion of cells with structural aberrations excluding gaps was compared with that of the corresponding vehicle control using
Fisher's exact test [14]. The assay was considered positive when there was a statistically significant increase in the proportion of cells with structural aberrations (excluding gaps) at any concentration that exceeded the historical vehicle control range, and the effect was reproducible.

\section{Mouse bone marrow micronucleus test}

The micronucleus test was conducted following the method of Schmid [15] and following the recommendations of the corresponding OECD guideline [16]. CD-1 mice of the $\mathrm{Crl}: \mathrm{CD}-1$ (ICR)BR strain were obtained from Charles River Laboratories (UK). All procedures involving animals and their care were conducted in strict conformity with the European Community and local Guide for the Care and Use of Laboratory Animals $[17,18]$, and the protocol was reviewed and approved by the testing facility ethical committee. The animals underwent a minimum 5-day acclimatization period to the environmental conditions of the room before the beginning of the assay. Animals were randomly allocated in groups of up to 5 animals and housed in Makrolon ${ }^{\circledR}$ cages with sawdust bedding. Animals were housed in rooms with temperature and relative humidity set at target values of $22^{\circ} \mathrm{C}$ and $30-70 \%$, respectively; lighting was controlled to give a 12 -h light-dark cycle; air conditioning guaranteed a minimum of 18 volume air changes per hour. They had access ad libitum to water and commercial rodent diet (Panlab SL, Spain).

On the day of dosing animals were approximately 8-9 weeks of age and in a weight range of $29-39 \mathrm{~g}$ for males and $23-28 \mathrm{~g}$ for females. Animals were dosed by oral route (gavage) at a dose volume of $10 \mathrm{~mL} / \mathrm{kg}$. The animals were weighed immediately before administration and received a weight-matched volume of vehicle, formulated test substance, or positive control. Based on a preliminary study, enflicoxib doses of 500, 1000 and $2000 \mathrm{mg} / \mathrm{kg}$ were selected. Groups of 5 male and 5 female animals each received either vehicle ( $0.52 \%$ Methylcellulose), CP $(50 \mathrm{mg} / \mathrm{kg})$ or enflicoxib at each of the stated doses and were sacrificed by cervical dislocation 24 hours after administration. Two further groups receiving the vehicle or the enflicoxib high dose were sacrificed 48 hours after administration ( $\vee$ Table 3). Immediately after euthanasia, the femurs were dissected, bone marrow extracted, placed on a slide containing a drop of foetal calf serum (Sigma, UK) and a direct smear was obtained (two slides per animal). Smears were fixed with methanol and stained with $5 \%$ Giemsa. Slides were coded and examined under light microscopy (Olympus $\mathrm{BH} 2$ ). For each animal, the relative proportion of polychromatic erythrocytes (PCE) and normochromatic erythrocytes (NCE) was determined by counting a total of 1000 erythrocytes. The number of micronucleated polychromatic erythrocytes (MNPCE) among 2000 PCE was determined. A total of 1000 normochromatic erythrocytes (NCE) was also observed and the number with micronuclei was also recorded. The number of MNPCE in each treated group (males and females separately and combined) were compared with the corresponding vehicle group by means of the Dunnett's test [19] after rank transformation of data. The result was considered positive when there was a statistically significant increase $(p<0.05)$ in the frequency of MNPCE, at least at one dose, that exceeded the historical vehicle control range. 


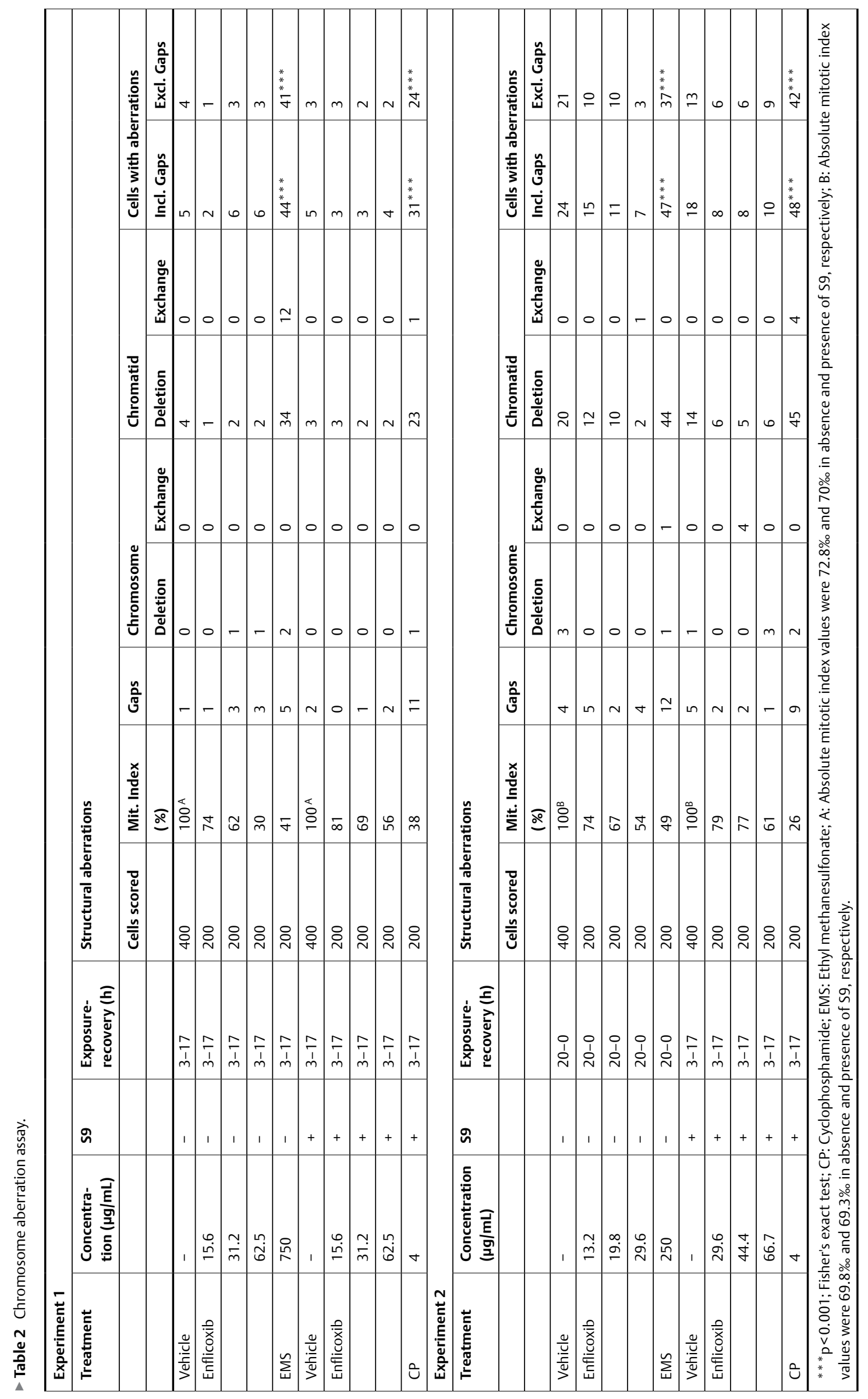


- Table 3 Single dose mouse micronucleus test.

\begin{tabular}{|l|l|l|l|l|l|l|}
\hline Sampling & Treatment & Dose & $\mathbf{N}$ & PCE/NCE & MNPCE/1000 PCEs & MNNCE/1000NCEs \\
\hline \multirow{2}{*}{ time } & & $\mathbf{( m g / k g )}$ & & (mean \pm SD) & (mean \pm SD) & (mean \pm SD) \\
\hline \multirow{4}{*}{$24 \mathrm{~h}}$. & Vehicle & - & 10 & $1,31 \pm 0,44$ & $1,3 \pm 0,4$ & $1,1 \pm 1,1$ \\
\cline { 2 - 8 } & Enflicoxib & 500 & 10 & $1,49 \pm 0,32$ & $1,9 \pm 0,8$ & $0,7 \pm 0,5$ \\
\cline { 2 - 7 } & & 1000 & 10 & $1,92 \pm 0,61$ & $1,8 \pm 1,2$ & $1,1 \pm 0,9$ \\
\cline { 2 - 7 } & & 2000 & 10 & $1,53 \pm 0,76$ & $1,8 \pm 0,9$ & $1,2 \pm 0,6$ \\
\cline { 2 - 7 } & CP & 50 & 10 & $0,85 \pm 0.29$ & $31,1^{* * *} \pm 14.3$ & $1,8 \pm 1,5$ \\
\hline \multirow{2}{*}{$48 \mathrm{~h}}$. & Vehicle & - & 10 & $1,53 \pm 0,52$ & $1,6 \pm 0,6$ & $0,6 \pm 0,7$ \\
\cline { 2 - 7 } & Enflicoxib & 2000 & 10 & $1,57 \pm 0,35$ & $2,2 \pm 1,5$ & \\
\hline \multirow{2}{*}{$* * *$} \\
\cline { 2 - 7 }
\end{tabular}

\section{Results}

\section{Ames test}

In the preliminary study with strain TA100, compound precipitation was observed at the two highest tested concentrations of 1667 and $5000 \mu \mathrm{g} /$ plate. However, as these concentrations were not associated with marked toxicity or interfered with the scoring of revertants, a concentration range of up to $5000 \mu \mathrm{g} /$ plate was tested in the main study. In the two independent conducted assays of the main study, enflicoxib was tested at concentrations of up to $5000 \mu \mathrm{g} /$ plate both in presence and absence of a rat liver metabolic activation system (S9-mix). Under all tested conditions, no increase in the number of revertants compared to the vehicle control values were observed. Results are shown in $>$ Table 1. In Experiment 1 , evidence of cell cytotoxicity, as shown by a reduction (exceeding $50 \%$ ) in the number of colonies compared to the vehicle control, were observed in strains TA98, TA1535 and TA1537 at concentrations $\geq 1667 \mu \mathrm{g} /$ plate, in the presence of metabolic activation. Precipitation of enflicoxib in the culture plates was observed in the whole battery of strains at concentrations $\geq 1667 \mu \mathrm{g} /$ plate, in the presence and in the absence of metabolic activation. Likewise, test item precipitation was also observed at the $556 \mu \mathrm{g} /$ plate concentration, in the absence of metabolic activation, in strains TA98, TA1535 and E. coli WP2 uvrA pKM101.

In Experiment 2, a reduction (exceeding $50 \%$ ) in the number of colonies compared to the vehicle control was observed in strains TA 98, TA1537 and E. coliWP2 uvrA pKM101 at concentrations $\geq 1667 \mu \mathrm{g} /$ plate, and in strain TA1535 at the $5000 \mu \mathrm{g} /$ plate concentration, in the presence of metabolic activation. In the absence of metabolic activity, signs of cytotoxicity were observed in strain TA1537 at the $5000 \mu \mathrm{g} /$ plate concentration. Test item precipitation was observed in the whole battery of strains at concentrations $\geq 1667 \mu \mathrm{g} /$ plate, in the presence and in the absence of metabolic activation. Likewise, test item precipitation was also observed in strain TA98 at the $556 \mu \mathrm{g} /$ plate concentration, in the absence of metabolic activation. The positive controls employed in the assays produced clear increases in the number of revertants in comparison to the vehicle control. It was concluded that enflicoxib was not mutagenic in this bacterial system.

\section{Human lymphocyte chromosome aberration assay}

In Experiment 1, human peripheral blood lymphocytes were exposed to enflicoxib concentrations of $3.9,7.8,15.6,31.2,62.5$, $125,250,500$ and $1000 \mu \mathrm{g} / \mathrm{mL}$, both in the absence and presence of metabolic activation, for 3 hours. Concentrations $\geq 125 \mu \mathrm{g} / \mathrm{mL}$ proved to be extremely toxic, both in the absence and presence of S-9 mix, with almost complete absence of viable cells in the treated cultures. The next lower concentration of $62.5 \mu \mathrm{g} / \mathrm{mL}$, showed a decrease in the mitotic index down to 30 and $56 \%$ of the matching vehicle control value in the absence and presence of S-9 mix, respectively, and was selected as the high concentration for metaphase analysis. The 31.2 and $15.6 \mu \mathrm{g} / \mathrm{mL}$ concentrations were selected as intermediate and low concentrations, respectively. Results of the slide examination are shown in > Table 2.

In Experiment 2, human peripheral blood lymphocytes were exposed to enflicoxib concentrations of 5.8, 8.8, 13.2, 19.8, 29.6, 44.4 and $66.7 \mu \mathrm{g} / \mathrm{mL}$ in the absence of metabolic activation (20 hours) and at concentrations of 13.2, 19.8, 29.6, 44.4, 66.7 and $100 \mu \mathrm{g} / \mathrm{mL}$ in the presence of metabolic activation ( 3 hours). In the absence of metabolic activation, concentrations $\geq 44.4 \mu \mathrm{g} / \mathrm{mL}$ proved to be extremely toxic with a null or very small number of metaphases present. The next lower concentration of $29.6 \mu \mathrm{g} / \mathrm{mL}$, that showed a decrease in the mitotic index down to $54 \%$ of the vehicle control value, was selected as the highest concentration for metaphase analysis. The 19.8 and $13.2 \mu \mathrm{g} / \mathrm{mL}$ concentrations were selected as intermediate and low concentrations, respectively. In the presence of S-9 mix, the highest tested concentration $(100.0 \mu \mathrm{g} / \mathrm{mL})$ proved to be extremely toxic, with total absence of cell material in the obtained preparations. The next lower concentration of $66.7 \mu \mathrm{g} / \mathrm{mL}$, showed a decrease in the mitotic index down to $61 \%$ of the vehicle control value and was selected as the high concentration for metaphase analysis. The concentrations of 44.4 and $29.6 \mu \mathrm{g} / \mathrm{mL}$ were selected as intermediate and lowest concentrations, respectively.

Both in Experiment 1 and 2, no increase in the number of structural or numerical chromosomal aberrations was observed in cultures treated with enflicoxib under any of the test conditions. The positive controls EMS and CP produced marked and statistically significant increases $(p<0.001)$ in the number of chromosomal aberrations, in absence and presence of metabolic activation, respectively, confirming the sensitivity of the test system. It was concluded that enflicoxib did not show genotoxic activity in this in vitro experimental assay. 


\section{Mouse bone marrow micronucleus test}

No mortality or clinical signs were recorded among animals receiving enflicoxib in the micronucleus test. Results of bone marrow examination are shown in $\triangleright$ Table 3. There was no effect of enflicoxib administration on PCE/NCE ratio at any dose level or sampling time. The mean frequency values of MNPCEs in the different enflicoxib treated groups were similar to those of their corresponding vehicle treated groups. The positive control CP induced, at the 24 hours sampling time, a slight decrease in the PCE/NCE ratio and a marked and statistically significant increase $(p<0.001)$ in MNPCE frequency, confirming the sensitivity of the test system. It was concluded that enflicoxib showed no potential for genotoxic activity in this in vivo assay.

\section{Discussion}

The selective COX-2 inhibitor enflicoxib was assessed for genotoxic potential by means of a battery of genotoxicity assays, comprising a bacterial reverse mutation assay (Ames test), a human lymphocyte chromosome aberration assay, and a mouse bone marrow micronucleus test. Testing for genotoxicity aims at identifying the potential to cause DNA damage, for this being considered essential for the induction of carcinogenesis and hereditary defects. Compounds that are positive for genotoxicity are considered being potentially carcinogens and/or mutagens in animals and humans. Though the regulatory requirement for assessing the genotoxic potential of veterinary drugs in a strict sense is formulated in the context of the safety of "veterinary drug residues in human food" [8] or the "safety for the user" [20], thereby placing its main focus on human risk, it will undoubtedly also apply to the risk imposed to the veterinary target animal species, this being particularly relevant for pet-animal species.

Within the so called "standard battery" of genotoxicity assays, the in vitro studies are generally considered to be the most sensitive for detecting genotoxic carcinogens, a contributing factor being that the exposure of the target cells is less problematic compared with in vivo assays. To this respect, in the in vitro assays conducted during our investigations, i. e. Ames test and human lymphocyte chromosome aberration assay, enflicoxib was clearly shown to lack genotoxic activity even when tested at concentrations that were associated to sings of cytotoxicity. In the Ames test, this was manifested as a reduction in the number of revertants at concentrations of $\geq 1667 \mu \mathrm{g} /$ plate. In the chromosome aberration assay, there was an absence of viable cells at concentrations of $\geq 125$ and $\geq 44.4 \mu \mathrm{g} / \mathrm{mL}$ in the absence of metabolic activation ( 3 and $20 \mathrm{~h}$ exposure, respectively), and at $\geq 100 \mu \mathrm{g} / \mathrm{mL}$ in the presence of metabolic activation ( $3 \mathrm{~h}$ exposure). The potential for enflicoxib to produce cytotoxic effects in bacterial and/or mammalian cells at concentrations that are within the range of the regulatory required test concentrations for assessing genotoxicity, is shared by other structurally related drugs pertaining to the same pharmacological class (COX-2 inhibitors), such as celecoxib (Celebrex ${ }^{\circledR}$ ) and valdecoxib $\left(\right.$ Bextra $\left.{ }^{\circledR}\right)[21,22]$. Celecoxib was reported to be toxic in the different tested bacterial strains (TA97a, 98, TA100, TA1535, TA1538) at concentrations of $\geq 500 \mu \mathrm{g} /$ plate, while no such effect was reported for valdecoxib. When assessed for the in vitro induction of chromosomal aberrations in mammalian cells ( $\mathrm{CHO})$, marked cytotox- icity was reported at concentrations of $\geq 80 \mu \mathrm{g} / \mathrm{mL}$ for celecoxib, and of $\geq 117 \mu \mathrm{g} / \mathrm{mL}$ or $\geq 75 \mu \mathrm{g} / \mathrm{mL}$ ( 4 and $24 \mathrm{~h}$ exposure, respectively) for valdecoxib. As for enflicoxib, both compounds were reported to lack clastogenic activity. However, for celecoxib an increased incidence of cell endoreduplication was reported when treated in presence of metabolic activation at $\geq 30 \mu \mathrm{g} / \mathrm{mL}$ [21]. Presence of endoreduplication is not considered to necessarily indicate potential for spindle damage and aneuploidy, and there is evidence that endoreduplication may indicate cell cycle perturbation. [23]. On the contrary, the COX-2 inhibitor parecoxib was reported to produce chromosomal aberrations in $\mathrm{CHO}$ cells after short term exposure (4 hours) both in the absence and the presence of S9, although this genotoxic effect was not reproduced when tested in vivo for genotoxicity [24].

In vivo assays are considered a pivotal component in the overall assessment of genotoxic potential, as they can take into account the biological processes of absorption, distribution, metabolism and excretion, which are not accounted for by in vitro assays. As such, they are considered to mimic closer the human situation and their results are given a great regulatory weight. Although failure of in vitro assays to detect relevant in vivo genotoxins is a rare occurrence, compounds such as procarbazine, urethane and benzene are examples of in vivo genotoxins which have proved difficult to be consistently detected in common regulatory in vitro assays $[25,26]$. When tested for in vivo genotoxic potential, enflicoxib was shown to lack genotoxic activity, either clastogenic or aneugenic, as evidenced by the lack of induction of MN in mouse bone marrow erythrocytes, after single dose oral administration of up to $2000 \mathrm{mg} / \mathrm{kg}$ dosages. The peak (Cmax) systemic exposure to enflicoxib achieved in mice after oral administration of a $2000 \mathrm{mg} / \mathrm{kg}$ dose, as determined in an independent pharmacokinetic study (unpublished results), was approximately 15 -times the highest exposure achieved in the target animal species under therapeutic conditions [27].

\section{Conclusions}

Enflicoxib was shown to lack genotoxic potential when thoroughly assessed in a battery of genotoxicity assays which comprised, a bacterial reverse mutation assay (Ames test), a human lymphocyte chromosome aberration assay and a mouse bone marrow micronucleus assay. From the results obtained it is concluded that administration of enflicoxib would not pose a genotoxic risk to humans or target animal species.

\section{Conflicts of Interest}

JH and MS are employees of Ecuphar Veterinaria SLU (Animalcare group), who sponsored the study. AG declares no conflict of interest.

\section{References}

[1] Wagemakers $M$, van der Wal GE, Cuberes R et al. COX-2 inhibition combined with radiation reduces Orthotopic Glioma outgrowthby targeting the tumor vasculature. Transl Oncol 2009; 2: 1-7 
[2] EMA. European Medicines Agency. Daxocox. European Public Assessment Report (EPAR). July $16^{\text {th }}$ 2021. https://www.ema.europa. eu/en/medicines/veterinary/EPAR/daxocox

[3] Salichs M, Badiella L, Sarasola P et al. Efficacy and safety of enflicoxib for treatment of canine osteoarthritis: A 6-week randomised, controlled, blind, multicentre clinical trial. Vet Rec 2021; e949. doi:10.1002/vetr.949 Epub ahead of print. PMID: 34590318.

[4] Homedes J, Salichs M, Guzman A. Long-term safety evaluation of Daxocox ${ }^{\circledR}$ tablets (enflicoxib) in dogs after weekly oral administrations for seven months. BMC Vet Res 2021; 17: 205. doi:10.1186/ s12917-021-02910-0 PMID: 34082759; PMCID: PMC8173827.

[5] ICH guideline M3(R2) on non-clinical safety studies for the conduct of human clinical trials and marketing authorisation for pharmaceuticals. December 2009. EMA/CPMP/ICH/286/1995 https://www.ema.europa. eu/en/ich-m3-r2-non-clinical-safety-studies-conduct-human-clinicaltrials-pharmaceuticals

[6] VICH GL33 Guideline on studies to evaluate the safety of residues of veterinary drugs in human food: general approach to testing. EMEA/ CVMP/VICH/486/02-Rev.2. 20 april 2009 https://www.ema.europa.eu/ en/vich-gl33-safety-studies-veterinary-drug-residues-human-foodgeneral-approach-testing

[7] ICH S2(R1) (2012) Genotoxicity testing and data interpretation for pharaceuticals intended for human use. June 2012. EMA/CHMP/ ICH/126642/2008 https://www.ema.europa.eu/en/ich-s2-r1genotoxicity-testing-data-interpretation-pharmaceuticals-intendedhuman-use\#current-effective-version-section

[8] VICH GL23: Studies to Evaluate the Safety of Residues of Veterinary Drugs in Human Food: Genotoxicity Testing. 6 November 2014 EMA/ CVMP/VICH/526/2000 https://www.ema.europa.eu/en/vich-gl23studies-evaluate-safety-residues-veterinary-drugs-human-foodgenotoxicity-testing

[9] Maron DM, Ames BN. Revised methods for the Salmonella mutagenicity test. Mutat Res 1983; 113: 173-215. doi:10.1016/01651161(83)90010-9 PMID: 6341825.

[10] Organization for Economic Co-operation and Development (OECD) OECD guideline for testing of chemicals, No. 471. Genetic Toxicology: Bacterial Reverse Mutation Test 2020

[11] Dean B], Danford N. Assays for the detection of chemically-induced chromosome damage in cultured mammalian cells, in: S.Venitt, J.M.Parry (Eds.), Mutagenicity Testing: A practical approach.IRL Press; Oxford: 1984: pp. 187-232

[12] Organization for Economic Co-operation and Development (OECD) OECD guideline for testing of chemicals, No. 473. Genetic Toxicology: In vitro mammalian chromosome aberration test 1997

[13] An International System for Human Cytogenetic Nomenclature (1985) ISCN 1985. Report of the Standing Committee on Human Cytogenetic Nomenclature, Birth Defects Orig.Artic.Ser., 21, (1985) 1-117. PMID: 4041569.
[14] Richardson C, Williams JA, Allen JA et al. Analysis of data from in vitro cytogenetic assays, in: Statistical evaluation of mutagenicity test data, (UKEMS Guidelines subcommittee report, Part III), D.J. Kirkland. Cambrige University Press; 1989: pp. 141-154

[15] Schmid W. The micronucleus test. Mutat Res 1975; 31: 9-15. doi:10.1016/0165-1161(75)90058-8 PMID: 48190.

[16] Organization for Economic Co-operation and Development (OECD) OECD guideline for testing of chemicals, No. 474. Genetic Toxicology: Mammalian erythrocyte micronucleus test 1997

[17] Parliament E, Council E. 2010; DIRECTIVE 2010/63/EU on the protection of animals used for scientific purposes. EU Off. J L276

[18] Generalitat de Catalunya. (1997) DECRET 214/1997, of July 30th, on the regulation of the use of animals for animal experimentation and other scientific purposes. DOGC num. 2450.

[19] Dunnett CW. A multiple comparison procedure for comparing several treatments with a control. J Am Statist Assoc 1955; 50: 1096-1121. do i: $10.1080 / 01621459.1955 .10501294$

[20] Committee for medicinal products for veterinary use (CVMP). European Medicines Agency. Guideline on user safety for pharmaceutical veterinary medicinal products EMA/CVMP/543/03Rev. 115 March 2010 https://www.ema.europa.eu/en/user-safetypharmaceutical-veterinary-medicinal-products

[21] NDA Celecoxib 20-998, Celebrex (Celecoxib) Capsules 12/31/1998. U.S. Food and Drug Administration. https://www.accessdata.fda.gov/ drugsatfda_docs/nda/98/20998.cfm

[22] NDA Valdecoxib 21-341, Bextra (Valdecoxib) Tablets 11/16/01. U.S. Food and Drug Administration. https://www.accessdata.fda.gov/ drugsatfda_docs/nda/2001/21-341_Bextra.cfm

[23] Hilliard CA, Armstrong M], Bradt Cl et al. Chromosome aberrations in vitro related to cytotoxicity of nonmutagenic chemicals and metabolic poisons. Environ Mol Mutagen 1998; 31: 316-326. PMID: 9654240.

[24] EMEA, Dynastat, INN-Parecoxib CPMP/1166/02 1/20 EMEA 2004 Scientific Discussion, (2004) www.ema.europa.eu/ema/pages/ includes/document/opendocument. jsp? webContentld = WC500038649

[25] Müller L, Kikuchi Y, Probst G et al. 1999; ICH-harmonised guidances on genotoxicity testing of pharmaceuticals: evolution, reasoning and impact. Mutat. Res. 436: 195-225

[26] Tweats DJ, Blakey D, Heflich RH et al. 2007; Report of the IWGT working group on strategy/interpretation for regulatory in vivo tests II. Identification of in vivo-only positive compounds in the bone marrow micronucleus test. Mutat. Res 627: 92-105

[27] Homedes J, Salichs M, Solà J et al. Pharmacokinetics of enflicoxib in dogs: Effects of prandial state and repeated administration. J Vet Pharmacol Ther 2021. doi:10.1111/jvp.12995 Epub ahead of print. PMID: 34160092. 